\title{
WASTEWATER DISINFECTION BY SOLAR HETEROGENEOUS PHOTOCATALYSIS: EFFECT ON TETRACYCLINE RESISTANT/SENSITIVE Enterococcus strains
}

\author{
RIZZO L. ${ }^{1 *}$ \\ FERRO G. ${ }^{1}$ \\ MANAIA C.M. ${ }^{2}$
}

Received: $15 / 01 / 13$

Accepted: $13 / 02 / 14$

*to whom all correspondence should be addressed e-mail: I.rizzo@unisa.it

\author{
${ }^{1}$ University of Salerno \\ Via Giovanni Paolo II 132 \\ 84084 Fisciano (SA), Italy \\ ${ }^{2} C B Q F$, Universidade Católica Portuguesa \\ Rua Dr. A. Bernardino Almeida \\ 4200-072 Porto, Portugal
}

\begin{abstract}
Solar simulated heterogeneous photocatalysis (SSHP) with suspended $\mathrm{TiO}_{2}$ was investigated in the inactivation of tetracycline resistant/sensitive Enterococcus (TRE/TSE) strains in the effluent of an urban wastewater treatment plant (UWTP). The effect of solar simulated disinfection (SSD) on the inactivation of the same Enterococcus strains was investigated as control. SSHP process $\left(0.05 \mathrm{~g} \mathrm{I}^{-1}\right.$ of $\left.\mathrm{TiO}_{2}\right)$ was found to be effective in the inactivation of both Enterococcus strains with total inactivation ( $\sim 7$ log unit) observed after 60 min of irradiation. On the contrary, SSD process did not show any significant inactivation after $90 \mathrm{~min}$ of irradiation. The effect of both processes on the antibiotic resistance phenotypes of the surviving enterococci was also evaluated. TRE cells surviving the SSHP treatment showed that disinfection process did not affect the antibiotic resistance pattern after 45 min irradiation. The same was observed for the TSE strain. Accordingly, antibiotic resistance can spread into the receiving water body when antibiotic resistant strains survive to disinfection process.
\end{abstract}

Keywords: advanced oxidation processes, antibiotic resistant bacteria, bioindicator, urban wastewater, wastewater reuse.

\section{Introduction}

Because of the intensive use of antibiotics for human (domestic and hospital use), veterinary and agriculture purposes, these compounds are continuously released into the environment from different anthropogenic sources (Brown et al., 2006; Kümmerer, 2009; Grassi et al., 2013). In addition to the adverse effects as chemical pollutants of the environment, antibiotics are also associated with the spread of antibiotic resistant bacteria (ARB) and antibiotic resistance genes (ARGs). The contamination of the environment and the related risk for human health through the food chain is presently considered a serious public health problem as confirmed by the World Health Organization (WHO) which identified the development of antibiotic resistance as one of the major global threats to the human society (WHO, 2013).

Urban wastewater treatment plants (UWTPs) are suspected to be among the main anthropogenic reservoirs for the development of antibiotic resistance because of the simultaneous occurrence of antibiotics, ARGs and ARB (Novo and Manaia, 2010; Michael et al., 2013; Rizzo et al., 2013a). UWTPs are not designed to remove these contaminants and consequently they are released into the effluent 
almost unaffected, possibly promoting antibiotic resistance spread in the environment (Lupo et al., 2012). Moreover, wastewater reuse, especially for irrigation purposes in areas with limited rainfall, is a current practice, but the risk for human health related to the uptake of ARB is almost unknown (Fatta-Kassinos et al. 2011; Gatica and Cytryn, 2013).

Disinfection process (when used) should be the ultimate barrier for controlling antibiotic resistance spread before UWTP effluent disposal or reuse, but conventional disinfection processes (namely, chlorination and UV radiation) may not effectively control the release of ARB and ARGs (Rizzo et al., 2013b). This drawback calls for the study of new/alternative processes, such as advanced oxidation processes (AOPs), which have been successfully investigated in water/wastewater treatment and disinfection (Rizzo et al., 2008; Lofrano et al., 2009; Zapata et al., 2010; Rizzo et al., 2013c). Among AOPs, heterogeneous photocatalysis with $\mathrm{TiO}_{2}$ has recently emerged as an interesting water disinfection option (Dunlop et al., 2011; Robertson et al., 2012) because it does not result in the formation of toxic disinfection by-products compared to chemical disinfectants (Richardson et al., 1996) and it can be operated with solar radiation thus saving money for energy (Malato et al., 2009). Solar driven photocatalysis could be an interesting disinfection option alternative to conventional processes, in particular in arid and semi-arid areas, to improve the quality and safety of the effluent from small wastewater treatment plants (e.g., $<2000$ people equivalent) before reuse.

The most studied bacteria for antibiotic resistance in wastewater belong to the common indicators of faecal contamination, namely coliforms and enterococci. Among coliforms, Escherichia coli have been recently used as indicators of antibiotic resistance to evaluate the effect of conventional (Templeton et al., 2009; Rizzo et al., 2013b; Huang et al., 2013) and new disinfection processes (Rizzo et al., 2014a). The effect on antibiotic resistant enterococci strains was investigated using $\mathrm{TiO}_{2}$ photocatalysis (Tsai et al., 2010) and solar photo-Fenton (Michael et al., 2012), .

Tetracyclines belong to a group of broad-spectrum antibiotics generally used in the treatment of infections of the urinary and gastrointestinal tracts. Accordingly, tetracycline is one of the most frequently detected antibiotics in wastewater (Watkinson et al., 2007; Michael et al., 2013) and different Enterococcus spp. (among which Enterococcus faecalis and Enterococcus faecium) were found to be capable of acquiring resistance to tetracycline (Cauwerts et al., 2007).

In the present work, two Enterococcus spp. strains, one tetracycline resistant (TRE) and one sensitive (TSE) were first isolated from the effluent of a biologically treated urban wastewater and used as bioindicators to test the disinfection efficiency of solar driven $\mathrm{TiO}_{2}$ photocatalysis process. The effect of disinfection process was evaluated based on Enterococcus survival and antibiotic resistance of surviving Enterococcus colonies.

\section{Material and methods}

\subsection{Wastewater samples}

Wastewater samples were taken from an UWTP located in the province of Salerno (Italy), from the effluent of the biological process (activated sludge). The UWTP also receives sewage from a hospital. The samples were collected in sterilized $1 \mathrm{I}$ amber glass bottles and analyzed for $\mathrm{pH}, \mathrm{BOD}_{5}, \mathrm{COD}$, TSS and conductivity.

\subsection{Selection and identification Enterococcus strains}

Resistant/sensitive Enterococcus strains were isolated from UWTP effluent sample on Slanetz Bartely Agar (SBA) culture medium (20 g l $\mathrm{I}^{-1}$ tryptose, $5 \mathrm{~g} \mathrm{I}^{-1}$ yeast extract, $2 \mathrm{~g} \mathrm{I}^{-1}$ glucose, $4 \mathrm{~g} \mathrm{l}^{-1}$ dipotassium phosphate, $0.4 \mathrm{~g} \mathrm{I}^{-1}$ sodium azide, $10 \mathrm{~g} \mathrm{I}^{-1}$ bacteriological agar, $0.1 \mathrm{~g} \mathrm{I}^{-1} \mathrm{TTC}$ ), using the membrane filtration method. A resistant Enterococcus strain was selected on SBA culture medium supplemented with16 $\mathrm{mg} \mathrm{l}^{-1}$ of TET (the minimal inhibitory concentration according to EUCAST (2013) data base). Briefly, $5 \mathrm{ml}$ of wastewater or its serial dilutions were added to $45 \mathrm{ml}$ of saline solution and filtered through membranes; membranes were subsequently transferred on SBA culture medium and incubated 
for $48 \mathrm{~h}$ at $37^{\circ} \mathrm{C}$. A confirmation test was conducted by transferring the membranes with typical red colonies onto Bile Esculin Azide (BEA) agar (17 $\mathrm{gl}^{-1}$ tryptose, $3 \mathrm{~g} \mathrm{I}^{-1}$ peptone, $5 \mathrm{~g} \mathrm{I}^{-1}$ yeast extract, $10 \mathrm{gl}^{-1} \mathrm{ox}$ bile, $5 \mathrm{~g} \mathrm{l}^{-1}$ sodium chlorine, $1 \mathrm{gl}^{-1}$ esculin, $0.5 \mathrm{gl}^{-1}$ iron ammonium citrate, $0.15 \mathrm{gl}^{-1}$ sodium azide, $13 \mathrm{gl}^{-1}$ agar). Some colonies were randomly picked up and frozen in $15 \%$ glycerol Triptone Soy Broth (TSB) at $20^{\circ} \mathrm{C}$.

\subsection{Inoculum and sample preparation}

Autoclaved (15 min at $121{ }^{\circ} \mathrm{C}$ ) wastewater samples were inoculated with TRE and TSE strains. For disinfection experiments, fresh cultures of the selected strains were inoculated in $500 \mathrm{ml}$ sterile wastewater sample at a density of $10^{7}$ colony forming units (CFU) $100 \mathrm{ml}^{-1}$ ( $0.5 \mathrm{McF}$. the bacterial inactivation achieved, bacteria were enumerated by the spread plate method on SBA. Culture plates yielding corresponding to 20-200 colonies were the basis for bacterial counts.

\subsection{Photocatalytic tests}

Photocatalytic experiments were carried out in 2.2 I cylindrical glass batch reactor ( $13.0 \mathrm{~cm}$ in diameter) filled in with $500 \mathrm{ml}$ wastewater sample $(5.0 \mathrm{~cm}$ water height). The reactor was placed in a water bath to maintain the temperature constant (roughly $30^{\circ} \mathrm{C}$ ) during the experimental procedure. The wastewater solution was continuously stirred during the experiments. Solar irradiation was provided by a wide spectrum $250 \mathrm{~W}$ lamp equipped with a UV filter (Procomat, Italy), fixed at $40 \mathrm{~cm}$ from the upper water level in the reactor. A spectrometer model HR-2000 from Ocean Optics (Florida, USA), equipped with cosine corrector with Spectralon diffusing material, was used to measure irradiance spectra of UV lamp (emission spectrum 340-460 nm; average intensity: $53.46 \mu \mathrm{W} \mathrm{cm}$; max intensity (375 nm): 104.0 $\mu \mathrm{W} \mathrm{cm}{ }^{-2}$ ). $0.05 \mathrm{~g} \mathrm{TiO}_{2} \mathrm{I}^{-1}$ was used in photocatalytic experiments, according to our previous results (Rizzo et al., 2014b). The autoclaved wastewater sample with the $\mathrm{TiO}_{2}$ powder (Degussa P25) was sonicated for $5 \mathrm{~min}$ before inoculum addition. Control tests without any photocatalyst addition (solar photolysis tests) were also performed.

\subsection{Antibiotic resistance assay}

The antibiotic resistance patterns of the bacterial isolates prior to and after the photocatalytic treatment was tested by Kirby-Bauer method. Briefly, the colonies that survived to photocatalytic treatment and grew on SBA medium were selected (4-5 colonies randomly selected from each one agar/irradiation time) and transferred to $10 \mathrm{ml}$ physiological solutions, respectively, to achieve $10^{7} \mathrm{CFU}$ $100 \mathrm{ml}^{-1}$ (0.5 McFarland). Bacterial suspensions were spread onto Mueller Hinton agar (Biolife, Italy) using a sterile cotton swab. Antibiotic-impregnated discs of ampicillin (AMP) (10 mg), ciprofloxacin (CIP) (5 mg), tetracycline (TET) (30 mg) and vancomycin (VAN) (30 mg) (all from Biolife) were placed on the surface of each inoculated plate. After $24 \mathrm{~h}$ of incubation at $37{ }^{\circ} \mathrm{C}$, the diameters of antibiotic inhibition of growth were measured. The procedure was duplicated and the average values plotted. The results were compared with antibiotic resistance and inhibition diameter $(\mathrm{mm})$ of Enterococcus faecalis for Kirby-Bauer method available in EUCAST (2013) database and summarized in Table 1.

Table 1: Summary of antibiotic resistance and inhibition diameter values $(\mathrm{mm})$ of Enterococcus faecalis for AMP, CIP, TET and VAN (Kirby-Bauer method) available in EUCAST database (2013).

\begin{tabular}{lcccc}
\hline & AMP & CIP & TET & VAN \\
\hline Resistant (R) & $\leq 16$ & $\leq 15$ & $\leq 14$ & $<16$ \\
\hline Intermediate (I) & - & $16-20$ & $15-18$ & - \\
\hline Sensitive (S) & $\geq 17$ & $\geq 21$ & $\geq 19$ & $>16$ \\
\hline
\end{tabular}




\section{Results and discussion}

\subsection{Wastewater characteristics}

The wastewater characteristics of the sample taken from the effluent of the biological process meet the Italian standards (for the measured parameters) for wastewater disposal into surface water but do not meet the standard set by Italian legislator for TSS for wastewater reuse (Table 2).

\subsection{Selected Enterococcus strains}

In order to compare the effect of the solar photocatalytic process on Enterococcus strains, two colony types that maintained viability after treatment were characterized for the antibiotic resistance pattern (Table 1). In particular, one strain was chosen because was resistant to TET (and sensitive to CIP and VAN) (TRE) and the other one was chosen because did not show any resistance to the tested antibiotics (TSE). The occurrence of antibiotic resistant Enterococcus in UWTP effluents is quite common, in particular when mixed with hospital wastewater effluents. Vancomycin and ciprofloxacin resistant bacteria were detected in hospital effluent and in raw UWTP inflow, being significantly more prevalent in the hospital (Varela et al., 2013); in particular, most of the vancomycin resistant enterococci isolated from the hospital effluent presented multidrug-resistance phenotypes to different antibiotics among which ciprofloxacin and tetracycline.

Table 2: Comparison of wastewater sample characteristics with Italian standards for effluent disposal and reuse

\begin{tabular}{cccccc}
\hline & $\mathrm{pH}$ & $\begin{array}{c}\mathrm{BOD}_{5} \\
\left(\mathrm{mg} \mathrm{l}^{-1}\right)\end{array}$ & $\begin{array}{c}\mathrm{COD} \\
\left(\mathrm{mg} \mathrm{l}^{-1}\right)\end{array}$ & $\begin{array}{c}\mathrm{TSS} \\
\left(\mathrm{mg} \mathrm{l}^{-1}\right)\end{array}$ & $\begin{array}{c}\text { Conductivity } \\
\left(\mu \mathrm{cm}^{-1}\right)\end{array}$ \\
\hline UWWTP effluent & 7.89 & 15 & 35 & 28 & 1453 \\
\hline $\begin{array}{c}\text { Italian disposal standards } \\
\text { (D.Lgs 152/2006) }\end{array}$ & $5.5-9.5$ & 25 & 125 & 35 & - \\
\hline $\begin{array}{c}\text { Italian reuse standards } \\
\text { (D.M. 93/2006) }\end{array}$ & $6-9.5$ & 20 & 100 & 10 & 3000 \\
\hline
\end{tabular}

\subsection{Enterococcus strains inactivation by solar photocatalysis}

Solar simulated photocatalytic process showed a total inactivation of the two tested strains, after 60 minutes of exposure (Figure 1). In particular, a $98.627 \%$ inactivation efficiency of TRE strain was observed after 30 min irradiation time (average initial concentration as high as $1.8 \times 10^{7} \mathrm{CFU} 100 \mathrm{ml}^{-1}$ ), and a $99.965 \%$ after $45 \mathrm{~min}$ irradiation. A similar trend was observed on the sensitive strain (average initial density $1.3 \times 10^{7} \mathrm{CFU} 100 \mathrm{ml}^{-1}$ ): an inactivation of $95.106 \%$ was reached after 30 min of treatment and of $99.817 \%$ after $45 \mathrm{~min}$. In parallel, solar disinfection tests did not show any significant inactivation of both strains under the same conditions of photocatalytic tests.

These results seem to support the idea that Enterococcus may be used as indicator of the occurrence of antibiotic resistant Enterococcus (in particular, TET resistant) after disinfection process. Specifically, if the disinfection process effectively inactivates Enterococcus indicators we can expect the simultaneous inactivation of the resistant strains.

Moreover, despite of different bacteria respond to stress conditions in different ways, it was observed that our results are in agreement with a previous work where the photocatalytic process was investigated in the inactivation of antibiotic resistant E. coli strain (Rizzo et al., 2014b). In particular, $\mathrm{TiO}_{2}$ photocatalytic tests under solar simulated radiation and the same operating conditions showed that total inactivation ( 7 log unit) can be achieved after $60 \mathrm{~min}$ of irradiation. Xiong and Xu (2013), investigated the effect of a UVA/LED/TiO 2 system $\left(\mathrm{TiO}_{2}\right.$ particles coated reactor, $8000 \mu \mathrm{W} \mathrm{cm}{ }^{-2}$ light 
intensity) on the inactivation of an antibiotic resistant $E$. coli strain (ATCC 700891) containing ampicillin and streptomycin resistance markers and they observed a $4.5 \mathrm{log}$ unit inactivation $\left(6 \times 10^{4} \mathrm{CFU} \mathrm{ml}^{-1}\right.$ initial bacterial density) in approximately $90 \mathrm{~min}$ of irradiation time. Tsai et al. (2010), investigated the effect of $\mathrm{TiO}_{2}$ photocatalytic process on three clinical isolates antibiotic resistant bacteria, among which vancomycin-resistant Enterococcus faecalis (VRE). Differently from the present work, the authors operated the photocatalytic process under higher intensity irradiation $\left(400-800 \mu \mathrm{W} \mathrm{cm}{ }^{-2}\right.$ ) and photocatalyst loadings $\left(0.0625-0.125 \mathrm{~g} \mathrm{I}^{-1}\right)$. According to our results, they did not observe any significant effect on VRE inactivation under light irradiation. When the catalyst was added $\left(0.0625 \mathrm{~g} \mathrm{I}^{-1}\right.$, $\left.400 \mu \mathrm{W} \mathrm{cm}{ }^{-2}\right)$ inactivation drastically increased $\left(10^{3}-10^{5} \mathrm{CFU} \mathrm{ml}^{-1}\right.$ initial bacterial density), but total inactivation was not observed during the experiment (max irradiation time $90 \mathrm{~min}$ ). Total inactivation was observed in 20-25 min when light irradiation intensity was increased up to $800 \mu \mathrm{W} \mathrm{cm}$ and photocatalyst loading was increased up to $0.125 \mathrm{~g} \mathrm{I}^{-1}$. The effect on enterococci was also investigated using a different AOP, namely solar photo-Fenton, to evaluate both inactivation rate and resistance percentage (ratio between resistant and total enterococci) (Michael et al., 2012); the authors observed that total inactivation (initial density $\sim 2.5-4.0 \times 10^{2} \mathrm{CFU} \mathrm{ml}^{-1}$ ) took place after $180 \mathrm{~min}$ treatment under real solar radiation.

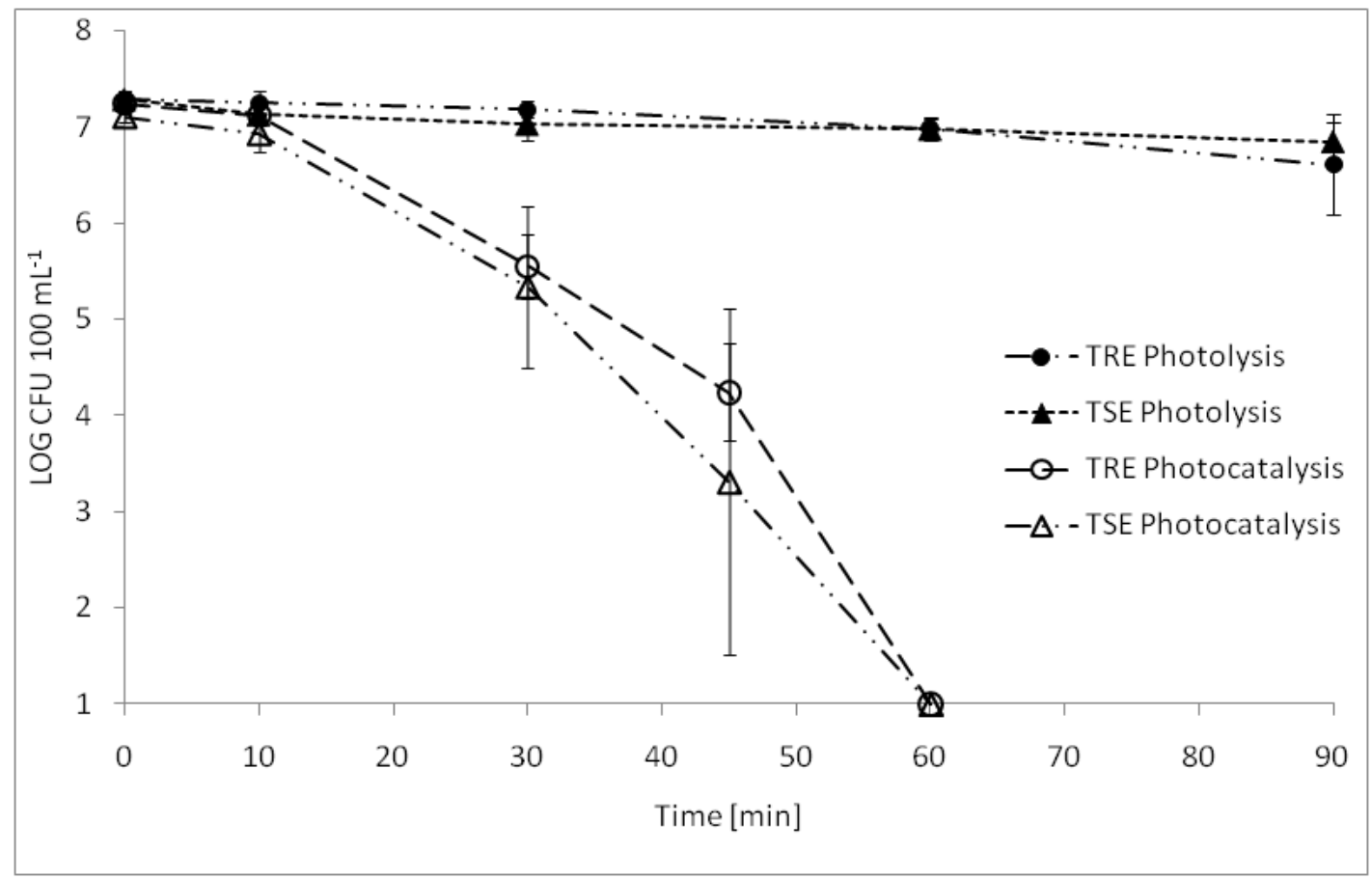

Figure 1. Inactivation rate of TRE and TSE strains under solar photolysis and photocatalytic disinfection $\left(0.05 \mathrm{~g} \mathrm{TiO}_{2} \mathrm{I}^{-1}\right)$.

\subsection{Effect of solar photocatalysis on antibiotic resistance}

The comparison of the average values of inhibition diameters for AMP, CIP, TET and VAN before disinfection treatment $(t=0)$ for TRE strain with the corresponding clinical breakpoints values for Enterococcus from EUCAST database (Table 1), shows that TRE strain is sensitive (S) to AMP, CIP and VAN antibiotics but resistant (R) to TET (Tables 3 and 4). The results of resistance test on the colonies that survived the photocatalytic treatment showed that disinfection process did not affect TRE strain resistance to AMP and CIP after 45 min irradiation (Table 3).

The photocatalytic treatment did not show any effect on TRE strain resistance to antibiotics tested (Table 3). Moreover, solar photolysis process did not show any effect on the inhibition diameter (no trend was observed) for all investigated antibiotics (Table 4). 
Table 3. Resistance test results on TRE strain before $(t=0)$ and after photocatalytic treatment: inhibition diameter $(\mathrm{mm})$ and resistance class.

\begin{tabular}{ccccc}
\hline$t(\min )$ & AMP & CIP & TET & VAN \\
\hline 0 & $24.3(\mathrm{~S})$ & $24.6(\mathrm{~S})$ & $10.0(\mathrm{R})$ & $20.0(\mathrm{~S})$ \\
\hline 10 & $23.8(\mathrm{~S})$ & $24.5(\mathrm{~S})$ & $10.0(\mathrm{R})$ & $20.0(\mathrm{~S})$ \\
\hline 30 & $24.0(\mathrm{~S})$ & $24.8(\mathrm{~S})$ & $10.0(\mathrm{R})$ & $20.0(\mathrm{~S})$ \\
\hline 45 & $31.5(\mathrm{~S})$ & $26.5(\mathrm{~S})$ & $10.0(\mathrm{R})$ & $20.0(\mathrm{~S})$ \\
\hline
\end{tabular}

Finally, both investigated processes did not affect resistance of TSE strain at all. The effect of photocatalytic process on an antibiotic resistant $E$. coli strain was investigated in a previous work (Rizzo et al., 2014b). When the E. coli suspension was disinfected the resistance of the survived colonies to CIP and VAN decreased (inhibition diameter increased from 12.8 to $13.8 \mathrm{~mm}$, and from 10.2 to $10.9 \mathrm{~mm}$, respectively) as irradiation time was increased (from 0 to $30 \mathrm{~min}$, respectively). In another work, the effect of solar photo-Fenton process on antibiotic resistance of enterococci was investigated in terms of resistance percentage (Michael et al., 2012). The authors observed that resistance decrease in ofloxacin (initial resistance percentage $\sim 20 \%$ ) and trimethoprim ( 10\%) resistant enterococci took place after 180 min treatment under real solar radiation.

Table 4. Resistance test results on TRE strain before $(\mathrm{t}=0)$ and after photolytic treatment: inhibition diameter $(\mathrm{mm})$ and resistance class.

\begin{tabular}{ccccc}
\hline $\mathrm{t}(\mathrm{min})$ & AMP & CIP & TET & VAN \\
\hline 0 & $19.0(\mathrm{~S})$ & $23.0(\mathrm{~S})$ & $10.0(\mathrm{R})$ & $20.0(\mathrm{~S})$ \\
\hline 10 & $18.8(\mathrm{~S})$ & $22.5(\mathrm{~S})$ & $10.0(\mathrm{R})$ & $20.3(\mathrm{~S})$ \\
\hline 30 & $18.8(\mathrm{~S})$ & $22.5(\mathrm{~S})$ & $10.0(\mathrm{R})$ & $20.0(\mathrm{~S})$ \\
\hline 60 & $18.3(\mathrm{~S})$ & $22.3(\mathrm{~S})$ & $10.0(\mathrm{R})$ & $20.0(\mathrm{~S})$ \\
\hline 90 & $19.3(\mathrm{~S})$ & $22.5(\mathrm{~S})$ & $10.0(\mathrm{R})$ & $20.5(\mathrm{~S})$ \\
\hline
\end{tabular}

\section{Conclusions}

$\mathrm{TiO}_{2}$ photocatalysis was found to be effective in the inactivation of TRE and TSE strains selected from the effluent of biological process of an UWTP. Remarkably, photocatalytic disinfection tests showed comparable inactivation rates for both strains. Therefore, we can expect that if Enterococcus strains are effectively inactivated by photocatalytic process, antibiotic resistant Enterococcus strains (at least some of them) can be inactivated too. Accordingly, Enterococcus may be used as indicators of photocatalytic process efficiency on antibiotic resistant Enterococcus.

Antibiotic resistance of surviving TRE colonies was not significantly affected by the photocatalytic process. This result supports the belief that antibiotic resistance can spread into the receiving water body when antibiotic resistant strains survive to disinfection process.

\section{Acknowledgements}

Luigi Rizzo wishes to thanks University of Salerno for funding the project entitled "Trattamento avanzato di acque reflue urbane mediante fotocatalisi: effetto sui batteri resistenti agli antibiotici. (FARB, ex60\%-anno 2012). Additionally, the authors wish to thank COST for the support to Action "TD0803: Detecting evolutionary hotspots of antibiotic resistances in Europe (DARE)" and the ERASMUS programme. 


\section{References}

Brown K.D., Kulis J., Thomson B., Chapman T.H. and Mawhinney D.B. (2006), Occurrence of antibiotics in hospital, residential, and dairy effluent, municipal wastewater, and the Rio Grande in New Mexico, Science of the Total Environment, 366, 772-783.

Cauwerts K., Decostere A., De Graef E.M., Haesebrouck F. and Pasmans F. (2007), High prevalence of tetracycline resistance in Enterococcus isolates from broilers carrying the erm(B) gene, Avian Pathology, 36, 395-399.

Dunlop P.S.M., Ciavola M., Rizzo L. and Byrne J.A. (2011), Inactivation and injury assessment of Escherichia coli during solar and photocatalytic disinfection in LDPE bags, Chemosphere, 85, 1160-1166.

EUCAST, (2013), European Committee on Antimicrobial Susceptibility Testing, http://www.eucast.org/.

Fatta-Kassinos D., Kalavrouziotis I.K., Koukoulakis P.H. and Vasquez M.I., (2011), The risks associated with wastewater reuse and xenobiotics in the agroecological environment, Science of the Total Environment, 409, 3555-3563.

Gatica J. and Cytryn E. (2013), Impact of treated wastewater irrigation on antibiotic resistance in the soil microbiome, Environmental Science and Pollution Research, 20, 3529-3538.

Grassi M., Rizzo L. and Farina A., (2013), Endocrine disruptors compounds, pharmaceuticals and personal care products in urban wastewater: Implications for agricultural reuse and their removal by adsorption process, Environmental Science and Pollution Research, 20, 3616-3628.

Huang J.J., Hua H.Y., Wua Y.H., Wei B. and Lu Y. (2013), Effect of chlorination and ultraviolet disinfection on tetAmediated tetracycline resistance of Escherichia coli, Chemosphere, 90, 2247-2253.

Kümmerer K. (2009), Antibiotics in the aquatic environment - A review - Part I, Chemosphere, 75, 417-434.

Lofrano G., Rizzo L., Grassi M. and Belgiorno V. (2009), Advanced oxidation of catechol: a comparison among photocatalysis, Fenton and photo-Fenton processes, Desalination, 249, 878-883.

Lupo A., Coyne S. and Berendonk T. (2012), Origin and evolution of antibiotic resistance: the common mechanism of emergence and spread in water bodies, Frontiers in Microbiology, 3, 18.

Malato S., Fernández-Ibáñez P., Maldonado M.I., Blanco J. and Gernjak W. (2009), Decontamination and disinfection of water by solar photocatalysis: Recent overview and trends, Catalysis Today, 147, 1-59.

Michael I., Hapeshi E., Michael C., Varela A.R., Kyriakou S., Manaia C.M. and Fatta-Kassinos D. (2012), Solar photoFenton process on the abatement of antibiotics at a pilot scale: Degradation kinetics, ecotoxicity and phytotoxicity assessment and removal of antibiotic resistant enterococci, Water Research, 46, 5621-5634.

Michael I., Rizzo L., McArdell C.S., Manaia C.M., Merlin C., Schwartz T., Dagot C. and Fatta-Kassinos D. (2013), Urban wastewater treatment plants as hotspots for the release of antibiotics in the environment: A review, Water Research, 47, 957-995.

Novo A. and Manaia C.M. (2010), Factors influencing antibiotic resistance burden in municipal wastewater treatment plants, Applied Microbiology and Biotechnology, 87, 1157-1166.

Richardson S.D., Thruston A.D., Collette T.W., Patterson K.S., Lykins B.W. and Ireland J.C. (1996), Identification of $\mathrm{TiO}_{2} /$ UV Disinfection Byproducts in Drinking Water, Environmental Science \& Technology, 30, 3327-3334.

Rizzo L., Della Rocca C., Belgiorno V. and Bekbolet M. (2008), Application of photocatalysis as a post treatment method of a heterotrophic-autotrophic denitrification reactor effluent, Chemosphere, 72, 1706-1711.

Rizzo L., Della Sala A., Fiorentino A. and Li Puma G. (2014b), Disinfection of urban wastewater by solar driven and UV lamp -TiO2 photocatalysis: Effect on a multi drug resistant E. coli strain, Water research, in press.

Rizzo L., Fiorentino A. and Anselmo A. (2013b), Advanced treatment of urban wastewater by UV radiation: Effect on antibiotics and antibiotic-resistant E. coli strains, Chemosphere, 92, 171-176.

Rizzo L., Manaia C., Merlin C., Schwartz T., Dagot C., Ploy M.C., Michael I. and Fatta-Kassinos D. (2013a), Urban wastewater treatment plants as hotspots for antibiotic resistant bacteria and genes spread into the environment: A review, Science of the Total Environment, 447, 345-360.

Rizzo L., Sannino D., Vaiano V., Sacco O., Scarpa A. and Pietrogiacomi D. (2014a), Effect of solar simulated N-doped $\mathrm{TiO} 2$ photocatalysis on the inactivation and antibiotic resistance of an $\mathrm{E}$. coli strain in biologically treated urban wastewater, Applied Catalysis B: Environmental, 144, 369-378. 
Rizzo L., Selcuk H., Nikolaou A.D., Meriç Pagano S. and Belgiorno V. (2013c), A comparative evaluation of ozonation and heterogeneous photocatalytic oxidation processes for reuse of secondary treated urban wastewater, Desalination and Water Treatment, Article in Press.

Robertson P.K.J., Robertson J.M.C. and Bahnemann D.W. (2012), Removal of microorganisms and their chemical metabolites from water using semiconductor photocatalysis, Journal of Hazardous Materials, 211-212, 161171.

Templeton M.R., Oddy F., Leung W.K. and Rogers M. (2009), Chlorine and UV disinfection of ampicillin-resistant and trimethoprim-resistant Escherichia coli, Canadian Journal of Civil Engineering, 36, 889-894.

Tsai T.M., Chang H.H., Chang K.C., Liu Y.-L. and Tseng C.C. (2010), A comparative study of the bactericidal effect of photocatalytic oxidation by $\mathrm{TiO}_{2}$ on antibiotic-resistant and antibiotic-sensitive bacteria, Journal of Chemical Technology \& Biotechnology, 85, 1642-1653.

Varela A.R., Ferro G., Vredenburg J., Yanik M., Vieira L., Rizzo L., Lameiras C. and Manaia C.M. (2013), Vancomycin resistant enterococci: From the hospital effluent to the urban wastewater treatment plant, Science of The Total Environment, 450-451, 155-161.

Watkinson A.J., Murby E.J. and Costanzo S.D. (2007), Removal of antibiotics in conventional and advanced wastewater treatment: implications for environmental discharge and wastewater recycling, Water Research, 41, 4164-4176.

World Health Organization (WHO), 2013, Antimicrobial resistance, Fact sheet N¹94, Updated May 2013, http://www.who.int/mediacentre/factsheets/fs194/en/.

Xiong P. and $\mathrm{Hu}$ J. (2013), Inactivation/reactivation of antibiotic-resistant bacteria by a novel UVA/LED/TiO 2 system, Water Research, 47, 4547-4555.

Zapata A., Oller I., Rizzo L., Hilgert S., Maldonado M.I., Sánchez-Pérez J.A. and Malato S. (2010), Evaluation of operating parameters involved in solar photo-Fenton treatment of wastewater: interdependence of initial pollutant concentration, temperature and iron concentration, Applied Catalysis B: Environmental, 97, 292-298. 